\title{
Danish ethics council rejects brain death as the criterion of death
}

\author{
B A Rix Danish Council of Ethics
}

\section{Author's abstract}

In Denmark, which alone in Western Europe has not accepted brain death as the criterion of death, the newly established Danish Council of Ethics has issued a report suggesting that in Denmark the criterion of death should still be the cessation of cardiac activity. The council bases its conclusion on the concept of death in everyday experience and its ethical implications.

\section{In Denmark brain death criteria are still a matter of debate}

Most Western European countries accept brain death as defining the death of a human being. In some countries, however, this issue has sown controversy among doctors, lawyers, theologians and the general public. This has notably been the case in Denmark, which alone in Western Europe has not accepted brain death as the criterion of human mortality.

In 1987, the Danish Ministry of Justice formulated a proposal for a law defining death; brain and heart death were both accepted as valid criteria. The purpose of the law was two-fold: it was to establish a legal framework for beating-heart organ transplants, and to ensure that the brain-dead did not undergo further treatment. The proposal proved controversial, and received only a first reading in the Danish Parliament before being withdrawn. One of the most significant critics of the proposed law was the newly established Danish Council of Ethics, which was created in 1988 by an act of Parliament.

The Danish Council of Ethics has various functions. It submits recommendations to the Minister of Health on the following issues: the protection of the fertilised human egg, the living embryo and the fetus; the possibility of genetic treatment of human gametes, fertilised human eggs, embryos and fetuses; the possibility of using new diagnostic techniques in order to discover congenital defects or diseases; and the regulation of the freezing of human gametes and fertilised human eggs. It advises health authorities at national and regional level on general ethical questions

\section{Key words}

Brain death; criteria of death. that relate to the provision of health care. And it may, on its own initiative, take up problems within the terms of its foundation (1).

The Danish Council of Ethics stated that a change in the criterion of death is an event of such significance that it should not be permitted without a major public debate on the ethical questions involved. The council itself initiated this debate, and established a working party to consider the matter.

Following discussion within the seventeen-member council, which comprises three doctors, two theologians, two lawyers, three teachers, two writers, one pharmacist, one social worker, one nurse, one biologist and one dentist, the Danish Council of Ethics issued a report suggesting that in Denmark the criterion of death should be the cessation of cardiac activity. If accepted, this position would be unique in Europe.

Four members of the council argued in favour of the criterion of brain death. The council based its conclusion on the following arguments (2).

\section{The problem}

The advent of new medical technology, for example the respirator, has affected the process of death. The possibility of extending 'life' beyond the point at which death would inevitably have ensued raises new ethical questions of very practical import. Though certain legal and medical dilemmas are solved by the brain death criterion, questions such as what is death and what conditions should be provided for the dying cannot be so summarily answered. Our experience of death transcends the medical and legal purviews, and relates to our most fundamental beliefs, attitudes and practices. The new medical technology necessitates a practical and precise definition of death, but this definition cannot be arrived at without a consideration of deep-lying human values.

\section{The concept and criterion of death}

It is important to distinguish the concept and the criterion of death. A concept of death elucidates the meaning of death; a criterion of death defines the time of death. Though science may define the instant of death, it is not competent to take up the ethical aspects of death in all their religious, moral and, in short, 
human, complexity. Yet, from an ethical point of view, it is in the context of the latter considerations that a criterion of death must be selected. It is in this way that a concept of death can shed light on the criterion of death.

The concept of death is multifarious, and to specify what death means might seem a hopeless task. Here however the council has chosen to rely on a consensus view in modern philosophy, that ethical considerations must be grounded in everyday experience. Thus we must take as our guide in establishing a concept of death the everyday experience of death common to the individuals of a particular culture.

\section{The concept of death in everyday experience and its ethical implications}

In 'everyday life', the experience of death is either that of oneself or of others. The death of those known to ourselves is experienced in particular as the amputation of relationship and interdependence with the dead person. One relates to one's own death in prospect as one of the facts of life, and one also experiences it as the concrete process of dying.

One's relation to the death of others is determined by one's relation to the dying person. And death can be experienced as a process or an event. Moreover, the relatives may continue to experience the dead person, not only as a dead body but also as the being that has died.

It is this relationship, which continues through and beyond the process of death, that implies the need for an ethical approach to the criterion of death; an approach, that is, defined by interpersonal relationship. The relatives of a dying person will normally experience death as a process divided into first knowledge, with the fear and shock engendered by the cause of death, and a subsequent perception of loss, and sentiment of grief. From the ethical point of view, it is important that medicine should not deprive the relative of the experience of any stage in this process, by artificially postponing the instant of apparent death.

There is no doubt that total destruction of the brain function means that the death process has begun and is irreversible. This is not in dispute. The question from the ethical point of view remains: when has the death process ended?

In everyday experience, the identity of a person comprises the integrality of consciousness and body, but, as identity relates no less to the body than to the mind, the process of death cannot be said to have ended while respiration and heartbeat continue, the body remains warm and the colours of the body normal. Such a state is, of course, compatible with brain death, and few people would be prepared to refer to a body in this state as a 'corpse'. This fact of experience is not altered by the artificial maintenance of these two signs. They continue to signify that life has not ended.

A further conclusion follows. Where total, irreversible destruction of brain function is diagnosed, all treatment should cease, so that the death process can continue and the relatives, if they so desire, be present at its end.

The definition of death in purely medical terms generally suggests that the instant at which death ensued can be pinpointed. The experience of death, we have said, continues beyond the point at which the dying person is pronounced dead, but the most commonly recognised criterion of death is cessation of heartbeat and respiration.

\section{The time and criterion of death in relation to the everyday experience of death}

The death criteria serve to define the exact time of death. The need for such criteria is clear; time of death has important psychological, social and legal implications. A clear criterion of death is important for the secure diagnosis of death. For the relatives, it is important to know that a person is dead and not dying. For society, it is important both to the medical profession to know when treatment can and should cease, and to the law to know when death can be publicly announced.

What criterion best fulfils these different requirements? Loss of consciousness resulting from total destruction of brain functions means the extinction of the person. But while signs of life remain, it may be difficult for others to acknowledge this extinction. The relatives may not consider permanent loss of consciousness equivalent to death. For them, the total cessation of respiratory, heart and brain functions constitutes visible proof of death.

For society, it is indispensable that the death criteria are precise and this requirement can be met by both death criteria. There is, moreover, a group of individuals in society, who, since they need organs transplanted from donors whose hearts are still beating, can only be helped if the brain death criterion is accepted. Their needs speak in favour of the criterion of brain death.

This difficulty is met if the cessation of all brain function is considered the irreversible onset, and the cessation of respiratory and cardiac activity the termination of the process of death.

To the Danish Council of Ethics this means that: (i) a person should be declared dead only when all brain, heart and lung function has definitely ceased; (ii) with the cessation of brain function, the person has entered the death process; (iii) the death process should not be prolonged after brain function has ceased; (iv) the time of death is given by the end and not the beginning of the death process, and (v) the sole purpose legitimating the extension of the death process is transplantation from beating heart donors, if the donor or his relatives have given their informed consent. The transplant procedure will end the death process but will not constitute the cause of the donor's death.

Following these guidelines, the Danish Council of Ethics has drawn up a proposal for a law on the protection of the dying. The council now awaits the 
reaction of the Danish Parliament.

Bo Andreassen Rix MD MA Psychology is a former Teacher in Medical Philosophy and is now Secretary of The Danish Council of Ethics.

\section{References}

(1) Act on establishment of an ethical council and regulation of certain forms of biomedical experiments. Ministry of Health, Denmark, 1987.

(2) The criteria of death. A Report from The Danish Council of Ethics, 1988 Dec. 